\title{
INTRODUCING NEW MEMBERS OF THE EDITORIAL BOARD
}

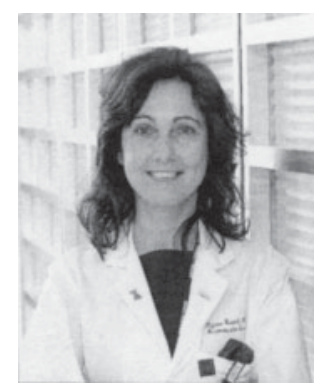

\section{Assistant Professor Tatjana Rundek, MD, PhD}

Dr. Tatjana Rundek is Assistant Professor of Neurology at Division of Stroke, Department of Neurology, Columbia University, City of New York, NY, USA. She is Director of the Research Neurosonology Laboratory, Department of Neurology, Columbia University. Dr. Rundek graduated from University of Zagreb, Croatia, where she received her medical degree. She received $\mathrm{PhD}$ degree in neuroscience and training in neurology at Sestre milosrdnice University Hospital in Zagreb, Croatia, where she was Chief Resident 1991-1992. She also received due training at Department of Neurology, New York Presbyterian Medical Center 1998-2002; fellowship training in neuroepidemiology and stroke at Columbia University in the City of New York, NY. Dr. Rundek is principal investigator (PI) on the NIH-funded project (R01) on genetic determinants of atherosclerosis, and on a number of clinical trials as site PI of the investigator initiated grants sponsored by various indus- tries. Dr. Rundek is co-investigator in the Northern Manhattan Stroke Study and Family Study, both NIHfunded grants. She is also co-investigator in several NIHfunded grants at other departments of Columbia University including oral infection and risk of stroke, cardiac disease and stroke, and atherosclerotic manifestations of primary hyperparathyroidism. Dr. Rundek is recipient of grants from the NIH, American Institute of Ultrasound in Medicine, Hazel K. Goddess Fund, Gilbert Baum Fund, Sanofi/BMS and Pfizer for research in the relationship of vascular risk factors, subclinical atherosclerosis and stroke. Dr. Rundek took the position of clinical coordinator in the Glycine Antagonist in Neuroprotection Trial, the largest international acute stroke neuroprotection study. Dr. Rundek has extensively lectured and published papers on stroke diagnosis, treatment, risk, and outcome. Her research has been focused on the genetic determinants and surrogate markers of atherosclerosis and stroke, and use of ultrasound for early detection, intervention and prevention of functional and structural changes of arterial wall in atherosclerotic inflammation. She is active member of the American Heart Association, American Academy of Neurology, American Institute of Ultrasound in Medicine, and European Society of Neurosonology and Cerebral Hemodynamics. She is also member of editorial boards of a number of professional journals including Stroke, Neurology, and The Journal of CardioMetabolic Syndrome. 